\title{
An Unusual Inflammatory Response to Implanted Deep Brain Electrodes
}

\author{
Peter S. Hughes, Jerry P. Krcek, Douglas E. Hobson, Marc R. Del Bigio
}

Can. J. Neurol. Sci. 2011; 38: 168-170

Since the late 1980s, deep brain stimulation (DBS) has gained increasing popularity in the treatment of movement disorders and other conditions. The U.S. Food and Drug Administration approved DBS of the thalamus for the treatment of Parkinson's disease and essential tremor in 1997, and DBS of the subthalamic nucleus and the globus pallidus internus for patients with Parkinson's disease in 2002'. Deep brain stimulation has also found a role in the management of dystonia, Tourette syndrome and obsessive-compulsive disorder ${ }^{2}$. By the end of 2007, more than 35,000 patients worldwide had undergone DBS therapy ${ }^{3}$.

Despite the large number of procedures, fewer than 50 autopsy reports have documented brain changes associated with the electrodes. In general, the placement of DBS electrodes and other types of invasive hardware into brain tissue is thought to induce only minor changes in the surrounding parenchyma, typically consisting of mild astroglial and microglial responses ${ }^{4}$. Here we report the autopsy findings of a man who underwent DBS for treatment of dystonia and at the time of death was found to have dense lymphocyte collections surrounding the electrodes.

\section{Case Description}

This man suffered from a generalized dystonic tremor, principally involving his upper extremities, with mild dystonia in his right leg. The symptoms had begun when he was 12-yearsold, but had not interfered with his daily activities until he was in his 30's. Two other family members reported similar' symptoms. Despite trials of several medications (including propranolol, topiramate, acetazolamide, lorazepam, levodopa and gabapentin), the dystonia and tremor progressed, eventually interfering with eating, writing, and carrying out his work as a farmer. At age 52 years, he underwent placement of a Medtronic Kinetra stimulator (Model 7428; Medtronic, Minneapolis MN) with bilateral quadripolar electrodes (Medtronic model 3387) in the ventro-intermediate thalamic nuclei. The stimulating electrodes are platinum-iridium and the wire leads are coated with $80 \mathrm{~A}$ urethane ${ }^{5}$, which is a polytetramethylene glycol-based polyurethane elastomer catalyzed with dibutyltin dilaurate ${ }^{6}$. He reported a substantial improvement in his tremor and dysarthria, and was able to function without any medication. During the entire treatment period the active electrodes bilaterally were the proximal (+) and penultimate proximal (-) electrodes. The initial parameters were pulse width $(60 \mu \mathrm{sec})$, rate $(130 \mathrm{~Hz})$, impedance (right $614 \mathrm{ohms}$ and left $793 \mathrm{ohms}$ ), and current (right $70 \mu \mathrm{A}$ and left $35 \mu \mathrm{A}$ ). Two years later the rate was increased to $160 \mathrm{~Hz}$ and the right side current was increased to $105 \mu \mathrm{A}$. One year later the left side current was increased to $70 \mu \mathrm{A}$. Ten months prior to death the settings were restored to the original levels; at that time impedance was $\sim 1050 \mathrm{ohms}$ bilaterally. Two months later (eight months prior to death), the impedance remained stable. Shortly thereafter the battery was replaced without complication. Seven months later, at the age of 56 years, the man collapsed and could not be resuscitated from ventricular fibrillation. No neurological changes had been reported in the months prior to death. The autopsy revealed a single focus of active myocarditis and multiple foci of myocardial fibrosis consistent with healed myocarditis, which may have caused an arrhythmia. Myocarditis due to viral infection is a well-recognized cause of sudden death $^{7}$.

Except for the electrode wires entering the frontal lobes, the brain $(1,545 \mathrm{~g})$ was grossly normal. Coronal sections through the cerebral hemispheres confirmed the electrode position within both thalami, terminating at the upper margin of the subthalamic nuclei (Figure A). Microscopic examination of brain tissue surrounding the lead paths showed mild loss of neurons, a thin collagen sheath, rare reactive astrocytes (demonstrated by glial fibrillary acidic protein (GFAP) immunostaining), and small collections of perivascular lymphocytes. Along the middle one $\mathrm{cm}$ of the right electrode array, likely corresponding to both active and inactive electrodes, multiple foci of perivascular lymphocytes were present. There were no multinucleate giant cells and no refractile material evident on polarized illumination. In the left thalamus a $1.5 \mathrm{~cm}$ electrode array site was evident. Inflammation was most prominent in the dorsal region, corresponding to active electrode sites (Figure B). On polarized illumination very rare multi-nucleate giant cells with streaks of refractile material (possibly polyurethane debris) were identified near the electrode tip in the ventral thalamus. These cells were surrounded by collagen with no lymphocytes in the immediate vicinity (Figure $\mathrm{C}$ ). Immunostaining showed roughly equal and intermingled populations of CD3 positive T-lymphocytes (CD4 greater than CD8) and CD20 immunoreactive B-lymphocytes. Immuno-staining for human leukocyte antigen (HLA-DR) demonstrated rare monocytes among the lymphocytes and

From the Sections of Neurology (PSH, DEH) and Neurosurgery (JPK), and Department of Pathology (MRDB), Health Sciences Centre; and The University of Manitoba, Winnipeg, Manitoba, Canada.

Received May 19, 2010. Final Revisions Submitted August 17, 2010. Correspondence to: Marc R. Del Bigio, Department of Pathology, University of Manitoba, Room 40] Brodie Centre, 727 McDermot Avenue, Winnipeg, Manitoba, R3E 3P5, Canada. 

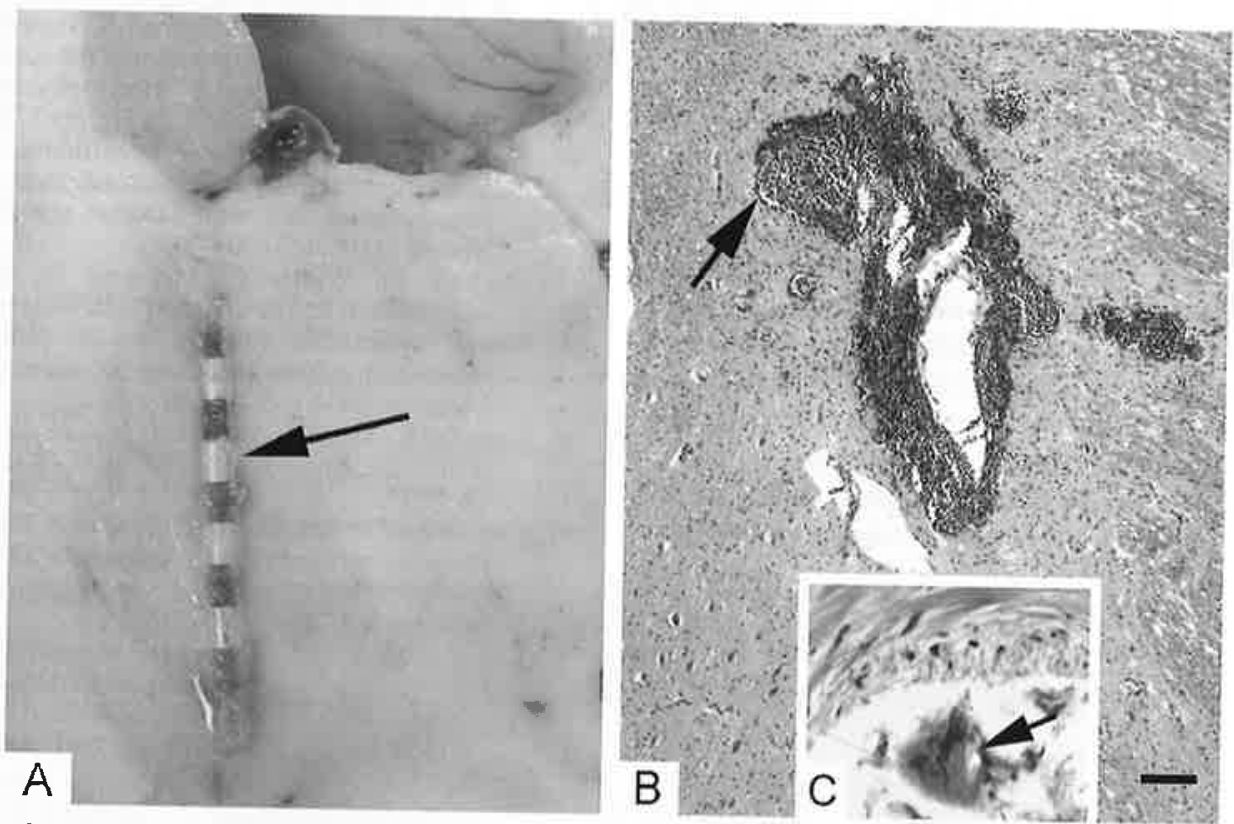

Figure: A. Photograph of coronal section through left thalamus showing electrode in situ. The two most dorsal electrodes were the active ones (arrow). $B$. Photomicrograph (hematoxylin and eosin stained section) showing dense collection of lymphocytes (arrow) adjacent to the dorsal electrodes on the left side. C. Photomicrograph (hematoxylin and eosin stained section, polarized light) showing a multinucleate giant cell that contains refractile material (arrow). There are no lymphocytes in the immediate vicinity of this cell, which was near the ventral electrode tip. Bar $=400 \mu m$ for $B$ and $20 \mu m$
for $C$.

microglial activation extending $\sim 300$ microns beyond the electrodes. Inflammation was negligible along the wire path. There was no evidence for meningitis or generalized encephalitis except for a single small focus of perivascular lymphocytes in the right caudate nucleus head. There was no microscopic evidence of disease that would explain the dystonia and tremor.

\section{DISCUSSION}

The perioperative risks associated with DBS are well documented, and include intracranial hemorrhage and infection at the implantation site ${ }^{8-10}$. Less clear, however, is the way in which brain tissue responds to chronically implanted hardware. Tissue reaction to stimulating electrodes could impair current delivery into the surrounding brain tissue ${ }^{11}$. The cellular mechanisms through which brain tissue responds to the introduction of a foreign body and the matter of electrode 'biocompatibility' have been reviewed ${ }^{12}$. Several animal studies have demonstrated that electrodes chronically implanted into brain tissue induce a transient localized microglial reaction. This is accompanied by a more sustained astrocytic reaction, which leads to the formation of an "insulating" sheath around the foreign body ${ }^{13}$. A chronic inflammatory response may be the driving force behind these histological changes, and it appears that the effect is related to the presence of a foreign body, rather than the trauma associated with electrode insertion ${ }^{14}$. Continuously active electrodes appear to cause a more marked reaction than intermittently active electrodes or electrodes through which no current is passed ${ }^{15}$. A few experimental reports caution that focal necrosis can occur with the application of an unbalanced monophasic current ${ }^{16}$. Other animal studies have suggested that the damage depends on the electrode material (e.g. stainless steel is more irritating than platinum-iridium) and possibly the charge density ${ }^{17}$.

Autopsies have been reported on fewer than 50 human subjects who died with DBS electrodes in place. These have revealed histological changes similar to those reported in the animal models. The largest study documented findings in the brains of eight Parkinson's disease patients whose electrodes had been operating for up to 70 months. Mild reactive astrogliosis was evident around the electrode lead tracks, but the surrounding neural parenchyma was well preserved. In two of the cases there was slight microglial activation and rare ("foreign body type") multinucleated giant cells ${ }^{18}$. A review of 37 published autopsies $^{4}$, as well as single case reports not covered in the review ${ }^{19-26}$, documented comparable features as well as collagenous encapsulation of the wire track. Only scattered lymphocytes in the vicinity of the electrode tracks have been reported ${ }^{24-29}$. In addition to the case reported here, we have examined an autopsy case of a 73-year-old man with Parkinson disease in whom tremor was treated with bilateral subthalamic stimulators for four years. The minor histological changes were similar to those previously reported in literature. One postmortem study used electron microscopy to examine fragments of brain tissue attached to 21 explanted DBS electrodes. The authors speculated that electron-dense inclusions in macrophages were fragments of polyurethane ${ }^{30}$.

This case stands out from previously published cases by virtue of the intense lymphocytic infiltrate at the electrode sites. There are several possible explanations for this. First, this might simply represent an extreme of the body's response to platinumiridium electrodes or polyurethane degradation products. 
However, our observation that the foreign body giant cells with refractile material were not associated with lymphocytes argues against this point. Second, this could represent a response to small quantities of residual dibutyltin dilaurate in the polyurethane coating of the wire leads, although there is no evidence in the toxicology literature to support such an inflammatory response ${ }^{31-33}$. Third, the reaction could represent a local exacerbation of foreign body inflammation in the setting of a systemic viral illness. Such a phenomenon has been suggested in the dermal implant literature ${ }^{34}$. Supporting this hypothesis is the fact that this man had evidence of similar focal inflammation in the heart. Furthermore, within a few weeks of the reported case, three other autopsy cases with incidental mild focal encephalitis were encountered. A variety of common, usually benign, seasonal enteroviruses are capable of causing myocarditis and encephalitis ${ }^{35}$. To what extent the brain inflammation contributed to this man's death is unknown.

\section{ACKNOWLEDGEMENTS}

The authors thank Shaton Allen and Susan Janeczko for technical assistance.

\section{Disclosures}

Dr. Del Bigio holds the Canada Research Chair in Developmental Neuropathology.

\section{REFERENCES}

1. Umemura A, Jaggi JL, Hurtig HI, et al. Deep brain stimulation for movement disorders: morbidity and mortality in 109 patients. J Neurosurg. 2003;98(4):779-84.

2. Awan NR, Lozano A, Hamani C, Deep brain stimulation: current and future perspectives. Neurosurg Focus. 2009;27(1):E2.

3. Volkmann J. Deep brain stimulation for Parkinson's disease. Parkinsonism Relat Disord. 2007;13 Suppl 3:S462-5.

4. van Kuyck K, Welkenhuysen M, Arckens L, Sciot R, Nuttin B. Histological alterations induced by electrode implantation and electrical stimulation in the human brain: a review. Neuromodulation. 2007;10:244-61.

5. Anonymous. DBS lead kit for deep brain stimulation 3387 / 3389 implant manual. Minneapolis MN: Medtronic; 2008.

6. Sacher E. A re-examination of the polyurethane reaction. J Macromolecular Sci B. 1979;16(4):525-38.

7. Davies MJ. The investigation of sudden cardiac death. Histopathology. 1999;34(2):93-8.

8. Volkmann J. Deep brain stimulation for the treatment of Parkinson's disease. J Clin Neurophysiol. 2004;21(1):6-17.

9. Voges J, Hilker R, Botzel K, et al. Thirty days complication rate following surgery performed for deep-brain-stimulation. Mov Disord. 2007;22(10):1486-9.

10. Bhatia $\mathrm{S}$, Oh $\mathrm{M}$, Whiting $\mathrm{T}$, Quigley $\mathrm{M}$, Whiting D. Surgical complications of deep brain stimulation. A longitudinal single surgeon, single institution study. Stereotact Funct Neurosurg. 2008;86(6):367-72.

11. Deuschl G, Herzog J, Kleiner-Fisman G, et al. Deep brain stimulation: postoperative issues. Mov Disord. 2006;21 Suppl 14:\$219-37.

12. Polikov VS, Tresco PA, Reichert WM. Response of brain tissue to chronically implanted neural electrodes. J Neurosci Methods. 2005; 148(1):1-18.

13. Griffith RW, Humphrey DR. Long-term gliosis around chronically implanted platinum electrodes in the Rhesus macaque motor cortex. Neurosci Lett. 2006;406(1-2):81-6.

14. Biran R, Martin DC, Tresco PA. Neuronal cell loss accompanies the brain tissue response to chronically implanted silicon microelectrode arrays. Exp Neurol. 2005;195(1):115-26.
15. Dauth GW, Defendini R, Gilman S, Tennyson VM, Kremzner L. Long-term surface stimulation of the cerebellum in the monkey. I. Light microscopic, electrophysiologic, and clinical observations. Surg Neurol. 1977;7(6):377-84.

16. Meissner W, Gross CE, Harnack D, Bioulac B, Benazzouz A. Deep brain stimulation for Parkinson's disease: potential risk of tissue damage associated with external stimulation - erratum. Ann Neurol. 2004;56(2):309-10.

17. Harnack D, Winter C, Meissner W, Reum T, Kupsch A, Morgenstern R. The effects of electrode material, charge density and stimulation duration on the safety of high-frequency stimulation of the subthalamic nucleus in rats. J Neurosci Methods. 2004;138(1-2):207-16.

18. Haberler C, Alesch F, Mazal PR, et al. No tissue damage by chronic deep brain stimulation in Parkinson's disease. Ann Neurol. 2000; 48(3):372-6.

19. McClelland S, 3rd, Vonsattel JP, Garcia RE, et al. Relationship of clinical efficacy to postmortem-determined anatomic subthalamic stimulation in Parkinson syndrome. Clin Neuropathol. 2007:26(6):267-75.

20. Guehl D, Vital A, Cuny E, et al. Postmortem proof of effectiveness of zona incerta stimulation in Parkinson disease. Neurology. 2008;70(16 Pt 2):1489-90.

21. Ghika J, Villemure JG, Miklossy J, et al. Postanoxic generalized dystonia improved by bilateral Voa thalamic deep brain stimulation. Neurology. 2002;58(2):311-3.

22. Patel NK, Heywood P, O'Sullivan K, McCarter R, Love S, Gill SS. Unilateral subthalamotomy in the treatment of Parkinson's disease. Brain. 2003;126:1136-45.

23. Talmant V, Esposito P, Stilhart B, Mohr M, Tranchant C. Stimulation des noyaux sous-thalamiques dans l'atrophie multisystematisee: a propos d'un cas anatomo-clinique. Rev Neurol (Paris). 2006;162(3):363-70.

24. Sun DA, Yu H, Spooner J, et al. Postmortem analysis following 71 months of deep brain stimulation of the subthalamic nucleus for Parkinson disease. J Neurosurg. 2008;109(2):325-9.

25. Pilitsis JG, Chu Y, Kordower J, Bergen DC, Cochran EJ, Bakay RA. Postmortem study of deep brain stimulation of the anterior thalamus: case report. Neurosurgery. 2008;62(2):E530-2; discussion $\mathrm{E} 2$.

26. Nielsen MS, Bjarkam CR, Sorensen JC, Bojsen-Moller M, Sunde NA, Ostergaard K. Chronic subthalamic high-frequency deep brain stimulation in Parkinson's disease - a histopathological study. Eur J Neurol. 2007;14(2):132-8.

27. Boockvar JA, Telfeian A, Baltuch GH, et al. Long-term deep brain stimulation in a patient with essential tremor: clinical response and postmortem correlation with stimulator termination sites in ventral thalamus. Case report. J Neurosurg. 2000;93(1):140-4.

28. Burbaud P, Vital A, Rougier A, et al. Minimal tissue damage after stimulation of the motor thalamus in a case of choreaacanthocytosis. Neurology. 2002;59(12):1982-4.

29. Jarraya B, Bonnet AM, Duyckaerts C, et al. Parkinson's disease, subthalamic stimulation, and selection of candidates: a pathological study. Mov Disord. 2003;18(12):1517-20.

30. Moss J, Ryder T, Aziz TZ, Graeber MB, Bain PG. Electron microscopy of tissue adherent to explanted electrodes in dystonia and Parkinson's disease. Brain. 2004;127(Pt 12):275563.

31. Guess WL, Haberman S. Toxicity profiles of vinyl and polyolefinic plastics and their additives. J Biomed Mater Res. 1968;2(3): 313-35.

32. Piver WT. Organotin compounds: industrial applications and biological investigation. Environ Health Perspect. 1973;4:61-79.

33. Alam MS, Husain R, Srivastava SP, Seth PK. Influence of dibutyltin dilaurate on brain neurotransmitter systems and behavior in rats. Arch Toxicol. 1988;61(5):373-7.

34. Lemperle G, Gauthier-Hazan N, Wolters M, Eisemann-Klein M, Zimmermann U, Duffy DM. Foreign body granulomas after all injectable dermal fillers: part 1. Possible causes. Plast Reconstr Surg. 2009;123(6):1842-63.

35. Anonymous. Enterovirus surveillance--United States, 2002-2004. MMWR Morb Mortal Wkly Rep. 2006;55(6):153-6. 